\title{
Development and Validation of a UV Spectrophotometric Method for Determination of Diacerein in Bulk and a Capsule Dosage Form
}

\author{
DALJIT KAUR, JASPREET KAUR* AND S. S. KAMAL \\ Rayat-Bahra Institute of Pharmacy, Hoshiarpur-146 001, India
}

\section{Kaur et al.: Development and Validation of a UV Spectrophotometric Method}

\begin{abstract}
A simple, accurate and selective UV-spectrophotometric method was developed for the estimation of diacerein in bulk and pharmaceutical dosage forms. The method was developed and validated according to International Conference on Harmonization (ICH Q2 R1) guidelines. The developed method was validated statistically with respect to linearity, range, precision, accuracy, ruggedness, limit of detection and limit of quantitation. The study was carried out in citrate buffer $\mathrm{pH} 6.0$ and $\lambda_{\text {max }}$ was found to be $258.8 \mathrm{~nm}$. Pure drug concentration was prepared in the range of $1-10 \mu \mathrm{g} / \mathrm{ml}$ and the linear regression analysis data showed good linear relationship with an $\mathbf{R}^{2}$ value of 0.999 . The limit of detection and limit of quantitation were found to be 0.675 and $1.189 \mu \mathrm{g} / \mathrm{ml}$, respectively. Recoveries were found to be in the range of 100.815 to $101.744 \%$ and $\%$ RSD was less than $2 \%$, which indicated that the developed method was accurate, precise, specific, rapid and suitable for the analysis of commercial samples.
\end{abstract}

Key words: Diacerein, UV-Spectrophotometer, recovery, accuracy, precision

Validation of an analytical procedure is defined as a process by which it is established that the performance characteristics of the procedure meet the requirements for the intended analytical applications in laboratory studies. The main objectives of any analytical measurement are to obtain consistent, reliable and accurate data. The results from method validation can be used to judge the quality, reliability and consistency of analytical results, which is an integral part of any good analytical practice ${ }^{[1]}$. The main parameters used for validation purpose are linearity and range, accuracy and precision, recovery, limit of detection and limit of quantitation.

Diacerein (DCN) is an anthraquinone derivative also known as diacetylrhein (fig. 1), which is chemically 4,5-diacetoxy-9,10-dioxo-9,10-dihydroanthracene2-carboxylic acid ${ }^{[2,3]}$ and is official in the Indian Pharmacopoeia (IP). It is a semisynthetic compound, derived by di-acetylation of rhein, has antiinflammatory, analgesic and antipyretic activity. Due to these pharmacological activities, it is used in the treatment of osteoarthritis, rheumatoid arthritis, epidermolysis bullosa and psoriasis ${ }^{[4-7]}$. The drug is also categorized as a disease modifying agent, which is a selective

*Address for correspondence

E-mail: jaspreet.meehnian@gmail.com

January-February 2019 inhibitor of interleukin-1 $\beta$. It also provides a protective effect on granuloma-induced cartilage breakdown by reducing the concentration of proinflammatory cytokines $^{[8-10]}$. It does not have any inhibitory effect on cyclooxygenase activity, due to which it does not affect prostaglandin synthesis and does not cause any gastroduodenal toxicity ${ }^{[10]}$. It also acts by stimulating the synthesis of proteoglycans and hyaluronic acid, the principle components of cartilage ${ }^{[11]}$. Metabolic by product of DCN is rhein with an anthraquinone ring, which also produces antiinflammatory effect by inhibiting interleukin- $1 \beta^{[12,13]}$.

Literature survey revealed that DCN is unstable under basic stress conditions specifically with sodium hydroxide when kept at room temperature for $48 \mathrm{~h}^{[14]}$, hence citric acid is used as a stabilizer in novel formulations ${ }^{[15,16]}$. No analytical method thus far has

This is an open access article distributed under the terms of the Creative Commons Attribution-NonCommercial-ShareAlike 3.0 License, which allows others to remix, tweak, and build upon the work non-commercially, as long as the author is credited and the new creations are licensed under the identical terms

Accepted 05 December 2018

Revised 30 April 2018

Received 18 January 2017

Indian J Pharm Sci 2019;81(1):124-128 
<smiles>CC(=O)Oc1cccc2c1C(=O)c1c(OC(C)=O)cccc1C2=O</smiles>

Fig. 1: Structure of DCN ${ }^{[16]}$

been reported for the estimation of DCN using citrate buffer $\mathrm{pH} 6.0$ and acetonitrile as co-solvent in bulk and pharmaceutical dosage forms. In the preparation of phosphate buffer (IP), sodium hydroxide is one of the ingredients used in the chemical formula. Due to the stability issue citrate buffer of $\mathrm{pH} 6.0$ was selected. An attempt has been made to develop a rapid, sensitive, precise and accurate UV spectrophotometric method by conducting systematic trials in the selected buffer for validation of pure drug in bulk and a capsule dosage form.

\section{MATERIALS AND METHODS}

Standard sample of DCN was a generous gift sample from Ami Lifesciences, Gujarat (India). The marketed DCN capsules (Leecrin) containing $50 \mathrm{mg}$ of DCN, manufactured by Allkind Healthcare (Himachal Pradesh, India) were purchased from market. All other chemicals used were of analytical grade. A double beam Systronics UV/Vis spectrophotometer, model UV-2201 (India) having a spectral bandwidth of $1 \mathrm{~nm}$, wavelength accuracy of $\pm 0.5 \mathrm{~nm}$ and a pair of $1 \mathrm{~cm}$ quartz cells was used to measure absorbance of the resulting solutions.

Accurately weighed quantity of $10 \mathrm{mg}$ of DCN was transferred into $10 \mathrm{ml}$ volumetric flask and then $1 \mathrm{ml}$ acetonitrile was added as a co-solvent and sonicated on bath sonicator for $5 \mathrm{~min}$. Then $5 \mathrm{ml}$ citrate buffer $\mathrm{pH} 6.0$ was added and again sonicated for $5 \mathrm{~min}$. Finally, the volume was made up with citrate buffer $\mathrm{pH}$ 6.0. The prepared solution was found to be a clear solution with a strength of $1000 \mu \mathrm{g} / \mathrm{ml}$.

One milliliter of the stock solution was taken in 100 $\mathrm{ml}$ volumetric flask and diluted up to the mark with citrate buffer $\mathrm{pH} 6.0$ to get the sample stock solution having the strength of $10 \mu \mathrm{g} / \mathrm{ml}$. Then further dilutions from $1-10 \mu \mathrm{g} / \mathrm{ml}$ were made. The standard solution of DCN $(10 \mu \mathrm{g} / \mathrm{ml})$ was scanned in the wavelength region of $200-400 \mathrm{~nm}$ (fig. 2) and the $\lambda_{\max }$ was found to be $258.8 \mathrm{~nm}^{[17,18]}$.
Linearity:

Linearity is defined by International Conference on Harmonization (ICH) as the ability of analytical procedure to obtain test results that are directly proportional to the concentration of analyte in the sample. Range of an analytical procedure is the interval from upper concentration to the lower concentration of analyte in the sample, which indicates that the followed analytical procedure has a suitable level of precision, accuracy and linearity ${ }^{[1,19]}$. To determine the linearity, 5 independent levels of calibration curve were analysed in the range of $1-10 \mu \mathrm{g} / \mathrm{ml}$. Absorbance of each solution was recorded at $258.8 \mathrm{~nm}$ against citrate buffer $\mathrm{pH}$ 6.0. The calibration curve was plotted and correlation coefficient with regression line equation for DCN was determined. Determination of intra-day precision was done by analysing DCN $(1-10 \mu \mathrm{g} / \mathrm{ml})$ at three different time points of the same day and the determination of the inter-day precision was determined by analysing DCN $(1-10 \mu \mathrm{g} / \mathrm{ml})$ at three different time points on different days ${ }^{[1,19,20]}$.

\section{Accuracy:}

Accuracy of the method was determined by percent recovery experiments performed at 3 different levels such as 50, 100 and $150 \%$. Known amount of standard DCN solutions were added to the preanalysed sample solutions. Absorbance was recorded and \% recovery was estimated by using calculated amount of drug in the following formula ${ }^{[1,21,22]} . \%$ Recovery $=\mathrm{A}-\mathrm{B} / \mathrm{C} \times 100$, where, A represents total amount of drug estimated, B represents amount of drug found on pre-analysed basis, $\mathrm{C}$ represents amount of pure drug added. Ruggedness of the proposed method was evaluated by applying same developed procedure to assay $10 \mu \mathrm{g} / \mathrm{ml}$ of DCN by using the same instrument by 2 different analysts on different days under same conditions. The obtained results were evaluated for the reproducibility ${ }^{[1,23]}$.

\section{Limit of detection (LOD) and limit of quantification (LOQ):}

ICH defines the limit of detection of an analytical method as the lowest amount of analyte in a sample,

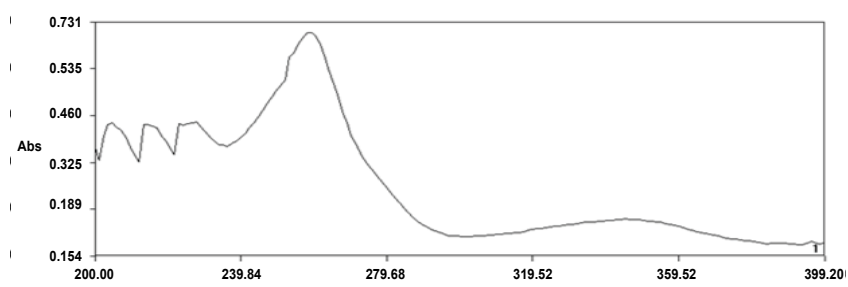

Fig. 2: UV Spectrum of pure DCN

UV Spectrum represents standard solution of DCN $10 \mu \mathrm{g} / \mathrm{ml}$ 
which can be detected but not necessarily quantitated as an exact value whereas limit of quantitation of an analytical procedure is the lowest amount of analyte in a sample, which can be determined quantitively with suitable precision and accuracy ${ }^{[1,8]}$. LOD and LOQ were calculated by using following formula: LOD = $3.3 \times \sigma / \mathrm{S}$ and $\mathrm{LOQ}=10 \times \sigma / \mathrm{S}$, where, $\sigma$ is the standard deviation of $y$-intercepts of regression line, $S$ is slope of the calibration curve.

Ten marketed capsules of DCN (Leecrin) containing $50 \mathrm{mg}$ drug per capsule were taken and emptied in a pestle and mortar. Weighed amount of the powder, equivalent to $10 \mathrm{mg}$ of DCN was transferred into the $10 \mathrm{ml}$ volumetric flask, $1 \mathrm{ml}$ acetonitrile was added as a co-solvent and sonicated on bath sonicator for $5 \mathrm{~min}$. Then $5 \mathrm{ml}$ citrate buffer $\mathrm{pH} 6.0$ was added and again sonicated for $5 \mathrm{~min}$, finally diluted up to the mark with citrate buffer $\mathrm{pH} 6.0$ to produce a solution of $10 \mathrm{ml}$. The prepared solution was found to be a clear having the strength $1000 \mu \mathrm{g} / \mathrm{ml}$, which formed the stock solution. From this stock solution $1 \mathrm{ml}$ of solution was taken and transferred to $100 \mathrm{ml}$ volumetric flask and diluted with pH 6.0 citrate buffer to get $10 \mu \mathrm{g} / \mathrm{ml}$ solution. From this solution, dilutions were prepared in the range $1-10 \mu \mathrm{g}$ and were analysed at $258.8 \mathrm{~nm}^{[24]}$.

Ten Leecrin capsules were taken and average weight was determined. Then contents were ground and mixed well. The powder of the sample equivalent to $10 \mathrm{mg}$ of DCN was accurately weighed (49 $\mathrm{mg}$ powder) and transferred into $10 \mathrm{ml}$ volumetric flask. Then $1 \mathrm{ml}$ of acetonitrile was added and final volume was adjusted using citrate buffer $\mathrm{pH}$ 6.0, sonicated for $5 \mathrm{~min}$ to get a clear solution of strength $1000 \mu \mathrm{g} / \mathrm{ml}$. Then the content of the flask was filtered using Whatman filter of pore size $0.45 \mu$. From this stock solution, $1 \mathrm{ml}$ of solution was taken and transferred to $100 \mathrm{ml}$ volumetric flask by adjusting the volume up to $100 \mathrm{ml}$, using citrate buffer $\mathrm{pH} 6.0$, which gave a solution of $10 \mu \mathrm{g} / \mathrm{ml}$ strength. This solution was prepared 5 times and the absorbance of each solution was determined at $254.8 \mathrm{~nm}$ and the concentration of DCN present in sample solution was calculated, there by the drug present per capsule was calculated $^{[18]}$.

\section{Statistical analysis:}

Statistical analysis was performed on obtained sample data (absorbance values of standard pure drug DCN and test samples prepared from market formulation Leecrin). Paired t-test was applied and hypothesis was tested at $5 \%$ level considering that there is no significant difference between the standard plot of pure drug and calibration curve of Leecrin.

\section{RESULTS AND DISCUSSION}

The linearity of DCN was found to be in the range of $1-10 \mu \mathrm{g} / \mathrm{ml}$ with linear correlation coefficient 0.999 (fig. 3A) and all the quantitative parameters were estimated is listed in Table 1 . The $\%$ RSD was found to be in the range of 0.514-1.253 for intra-day precision and 0.996-1.738 for inter-day precision (Table 2). Accuracy of the method was checked by the recovery studies at three different levels, i.e., 50, 100 and $150 \%$. The mean of the recovery for DCN was found to be $101.238 \%$ (Table 3 ). The obtained results listed in Table 4 were found to be reproducible, since there was no significant difference between analysts. Thus the proposed method was considered as rugged. The sensitivity of the method was assessed by determining the LOD and LOQ. The LOD and LOQ for DCN were found to be 0.675 and $1.189 \mu \mathrm{g} / \mathrm{ml}$, respectively. The linearity of the calibration curve (fig. 3B) showed that the proposed method could be successfully used for analysing a pharmaceutical dosage form without any interference from common excipients, which was further confirmed from statistical analysis.

The amount of DCN in the capsule formulation was accurately estimated with the developed method as

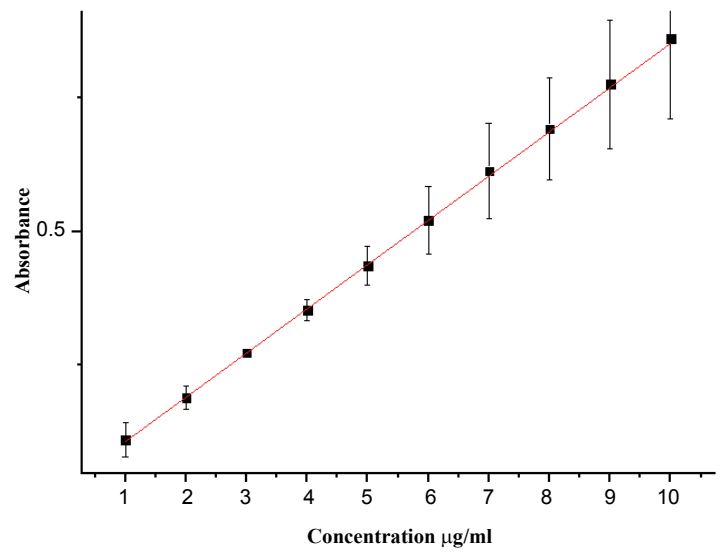

Fig. 3: Standard plot of pure DCN $y=0.083 x+0.022 ; R^{2}=0.999$

TABLE 1: QUANTITATIVE PARAMETERS OF UV SPECTROPHOTOMETRIC METHOD

\begin{tabular}{lc}
\hline Parameter & Result \\
\hline$\lambda_{\max }(\mathrm{nm})$ & 258.8 \\
Beer's law limits $(\mu \mathrm{g} / \mathrm{ml})$ & $1-10$ \\
Regression equation & $0.083 \mathrm{x}+0.022$ \\
Slope & 0.083 \\
Intercept & 0.022 \\
Correlation coefficient $\left(\mathrm{R}^{2}\right)$ & 0.999 \\
\hline
\end{tabular}


TABLE 2: RESULTS OF INTRA-DAY AND INTER-DAY PRECISION

\begin{tabular}{lcccccc}
\hline $\begin{array}{l}\text { Concentration } \\
(\mu \mathrm{g} / \mathrm{ml})\end{array}$ & \multicolumn{3}{c}{ Intra-day precision } & \multicolumn{3}{c}{ Inter-day precision } \\
\cline { 2 - 7 } & Absorbance $^{* *}$ & SD & \%RSD & Absorbance* & SD & \%RSD \\
\hline 2 & 0.261 & 0.022 & 0.749 & 0.293 & 0.033 & 0.996 \\
4 & 0.475 & 0.068 & 1.253 & 0.556 & 0.072 & 1.126 \\
6 & 0.676 & 0.041 & 0.514 & 0.711 & 0.144 & 1.738 \\
\hline
\end{tabular}

${ }^{* *}$ Average of five determinations

TABLE 3: RESULTS OF RECOVERY STUDIES

\begin{tabular}{lcccc}
\hline $\begin{array}{l}\text { Amount of sample } \\
(\boldsymbol{\mu g} / \mathrm{ml})\end{array}$ & $\begin{array}{c}\text { Amount of drug added } \\
(\boldsymbol{\mu} / \mathrm{ml})\end{array}$ & $\begin{array}{c}\text { Percent of spiked } \\
\text { sample }\end{array}$ & $\begin{array}{c}\text { Amount recovered }(\boldsymbol{\mu g} / \\
\mathrm{ml})\end{array}$ & $\begin{array}{c}\text { Percent } \\
\text { recovery }\end{array}$ \\
\hline 2 & 1 & $50 \%$ & 3.299 & 101.156 \\
2 & 2 & $100 \%$ & 4.320 & 101.744 \\
2 & 3 & $150 \%$ & 5.428 & 100.815 \\
\hline
\end{tabular}

TABLE 4: RUGGEDNESS OF THE METHOD BY TWO ANALYSTS ON DIFFERENT DAYS

\begin{tabular}{lcc}
\hline Test parameters & Analyst-I & Analyst-II \\
\hline Absorbance $^{*}$ & 0.829 & 0.826 \\
Concentration $(10 \mu \mathrm{g} / \mathrm{ml})^{*}$ & 9.728 & 9.692 \\
SD & 0.041 & 0.045 \\
$\%$ RSD & 0.416 & 0.462 \\
\hline
\end{tabular}

*Average of five determinations

TABLE 5: ASSAY OF CAPSULE FORMULATION

\begin{tabular}{lcccc}
\hline Formulation & $\begin{array}{c}\text { Label } \\
\text { claimed } \\
(\mathbf{m g})\end{array}$ & $\begin{array}{c}\text { Amount } \\
\text { recovered } \\
(\mathbf{m g})\end{array}$ & $\begin{array}{c}\text { \% Drug } \\
\text { recovered }\end{array}$ & \% RSD \\
\hline $\begin{array}{l}\text { Leecrin } \\
\text { capsule }\end{array}$ & 50 & $49.93 \pm 0.293$ & 99.860 & 0.586 \\
\hline
\end{tabular}

shown in Table 5, hence indicating that the method could be effectively applied to analyse different pharmaceutical dosage forms of DCN.

The observed value of ' $t$ ' comes out to be 0.216 , which was in the acceptance region in both one tailed as well two tailed test (two tailed test at 0.05 level of significance is 2.262 while level of significance for one tail test is 1.833 at 0.05$)$ even at the lowest level (0.01) of significance corresponding to 9 degrees of freedom. Hence null hypothesis $\left(\mathrm{H}_{0}\right)$ was rejected. It could be concluded that the method of validation is relevant as the difference is insignificant between the standard plot readings and calibration curve of pure drug and tested samples of Leecrin.

From the above results, it could concluded that the method developed for determination of DCN in bulk and a capsule dosage form was found to be simple, sensitive, accurate, precise, reproducible and economical. Purity of the drug peak was assessed by analysing the spectra, as shown in fig 2 . The $\mathrm{R}^{2}$ value of 0.999 and $\% \mathrm{RSD}<2$, indicated good results. The results obtained from interday precision provided evidence about the ruggedness of the analytical method due to the low value of
$\%$ RSD. The lowest value of LOD, obtained by proposed method indicated that the followed method was highly sensitive. Small but calculated changes did not affect the method, which indicated that the proposed method was found to be robust. \% RSD of pharmaceutical formulation was found to be $0.586 \%$, which showed that there was no interference from the excipients used in the formulation, which indicated the accuracy and reliability of the method. To ensure the specificity of developed method, 2 evaluation parameters (calibration and assay) were performed on Leecrin, which ensured that the developed method could be used for routine analysis for estimation of DCN in bulk and capsule dosage forms.

\section{Conflicts of interest:}

There is no conflict of interest.

\section{REFERENCES}

1. Validation of Analytical Methods [cited 2016 Nov 20]. Available from: http:/www.labcompliance.com/tutorial/ methods/default.aspx\#08_paramters.

2. Khan MI, Madni A, Saeed A, Mahmood MA, Rehman M, Ashfaq M. Formulation design and characterization of a non-ionic surfactant based vesicular system for the sustained delivery of a new chondroprotective agent. Braz J Pharm Sci 2015;51(3):608-15.

3. Indian Pharmacopoeia. 6th ed. Ghaziabad: Indian Pharmacopoeia Commission; 2010.

4. Garthe OM, Kothawade PS, Mahajan VR. Solubility Enhancement of Diacerein by Solid Dispersion Technique. Int J Pharm Res Allied Sci 2013;2(2):47-55.

5. Prasad P, Patil CC. Solubility Enhancement and Evaluation of Diacerein Using Cyclodextrin as Hydrophilic Carriers. J Pharm Res 2009;2(5):923-6.

6. Wally V, Kitzmueller S, Lagler F, Moder A, Hitzl W, Wolkersdorfer $\mathrm{M}$, et al. Topical diacerein for epidermolysis bullosa: a randomized controlled pilot study. Orphanet J Rare Dis 2013;8(69):1-3.

7. Napoli D, inventor; Laboratoire Medidom SA, assignee. Diacerein for use in treating psoriasis. European patent EP1248608B1. 2003 Nov 26. 
8. Gandhi SP, Dewani MG, Borole TC, Damle MC. Development and validation of stability indicating HPLC method for determination of Diacerein and Aceclofenac as bulk drug and in tablet dosage form. Int J Res Pharm Chem 2011;1(4):799-806.

9. Bruyère O, Burlet N, Delmas PD, Rizzoli R, Cooper C, Reginster JY. Evaluation of symptomatic slow-acting drugs in osteoarthritis using the GRADE system. BMC Musculoskelet Disord 2008;9(165):1-9.

10. Mahajan A, Singh K, Tandon VR, Kumar S, Kumar H. Diacerein: A New Symptomatic Slow Acting Drug for Osteoarthritis. J Med Educ Res 2006;8(3):173-5.

11. Medhi B, Singh PK, Prakash A, Sen R, Wadhwa S. Diacerein: A New Disease Modulating Agent in Osteoarthritis. IJPMR 2007;18(2):48-52.

12. Gupta K, Singhvi I, Bais S. U.V. Method for quantitative estimation of Diacerein from capsule Formulation. Asian J Pharm Anal 2013;3(4):124-6.

13. Nyola NK, Kalra N. Spectrophotometric Determination of diacerin in bulk and pharmaceutical formulation. Int J Pharm BioSci 2010;1:202-7.

14. Chauhan K, Choudhari V. Isolation, Identification and Characterization of alkaline degradant of Diacerein using LCMS. Pharmacophore 2015;6(4):189-95.

15. Jain A, Singh SK, Singh Y, Singh S. Development of Lipid Nanoparticles of Diacerein, an Antiosteoarthritic Drug for enhancement in bioavailability and reduction in its side effects. J Biomed Nanotech 2013:9(5);891-900.

16. Yang $\mathrm{M}, \mathrm{He} \mathrm{S}$, Fan $\mathrm{Y}$, Wanga $\mathrm{Y}$, Ge Z, Shan L, et al. Microenvironmental $\mathrm{pH}$-modified solid dispersions to enhance the dissolution and bioavailability of poorly watersoluble weakly basic GT0918, a developing anti-prostate cancer drug: Preparation, characterization and evaluation in vivo. Int J Pharm 2014;475(1-2):97-109.
17. Patil SB, Shete DK, Narade SB, Surve SS, Khan ZK, Bhise $\mathrm{SB}$, et al. Improvement in the dissolution profile of diacerein using a surfactant-based solid dispersion technique. Drug Discov Ther 2010:4(6);435-41.

18. Nayak S, Sarangi RR, Panda SK, Dash AK, Rath SK, Rath S. UV- spectrophotometric method for simultaneous estimation of paracetamol and ondansetron in bulk and their formulation. Int J Biol Pharm Res 2011;2(2):45-9.

19. Sreejith KR, Premalatha K. Novel spectrophotometric methods for estimation of diacerein from formulations. Int $\mathrm{J}$ Res Pharm Biomed Sci 2011;2:992-9.

20. Gurupadayya BM, Bharatheesha BM. Validated Spectrophotometric Method for the Assay of Diacerein in Bulk and Pharmaceutical Formulations. J Pharm Sci Res 2010;2(10):638-43.

21. Saurabh K, Dharamveer K. Development and Validation of analytical methods for Simultaneous Estimation of Diacerein and Aceclofenac in Bulk and Tablets using UV-visible spectroscopy. Int J ChemTech Res 2010;2(3):1816-22.

22. Kulkarni S, Chhabra G, Shivani M. Development and validation of UV spectrophotometric method for the determination of Risperidone in bulk and tablets formulation. Int J Pharm Chem 2012;2:10-4.

23. Sudhir MS, Mohan PM, Nadh RV. Simple and Validated Ultraviolet Spectrophotometric Method for the Estimation of Febuxostat in Bulk and Pharmaceutical Dosage Forms. Oriental J Chem 2013;29(1):235-40.

24. Harde M, Wankhede S, Chaudhari P. Development of validated UV spectrophotometric method for simultaneous estimation of Ibuprofen, Paracetamol and Caffeine in the bulk drug and marketed formulation. World J Pharm Res 2015;4(9):1428-36. 